\title{
Probabilistic modelling of the tensile related material properties of timber boards and finger joint connections
}

\author{
Gerhard Fink $\cdot$ Jochen Kohler
}

Received: 27 June 2014/Published online: 8 March 2015

(C) Springer-Verlag Berlin Heidelberg 2015

\begin{abstract}
In the present paper a probabilistic approach for modelling the tensile strength and tensile stiffness properties of timber boards and finger joint connections is presented. The approach includes the geometrical setup of timber boards (the position of knot clusters) and a hierarchical representation of two strength and stiffness related indicators. One indicator to describe the mean material properties of timber boards and one indicator to describe the lengthwise variability due to knots. Based on the two indicators the tensile strength and tensile stiffness of timber board sections and finger joint connections are estimated using material models. The application of the approach is illustrated. For this purpose, finger joint connections and timber boards with different length are simulated and the material properties are compared with values proposed in the literature.
\end{abstract}

\section{Introduction}

As a natural grown material timber has a large variability in its load bearing behaviour compared to other building materials. For engineering purposes, the variability can be subdivided into (a) the variability between the timber boards of one strength grade, and (b) the lengthwise variability within the timber boards. The variability between timber boards is related to different growth and sawing

\section{G. Fink ( ()}

ETH Zurich, Institute of Structural Engineering,

Stefano-Franscini-Platz 5, 8093 Zurich, Switzerland

e-mail: fink@ibk.baug.ethz.ch

\section{J. Kohler}

Department of Structural Engineering, NTNU Trondheim, Rich. Birkelandsvei 1A, 7491 Trondheim, Norway characteristics, e.g. growth region, sapwood-heartwood. Within structural timber the variability is highly dependent on morphological characteristics of the tree, especially on knots and their arrangement.

In the past, numerous models have been developed to describe the variability of the material properties. Wellknown examples for the stiffness variability are Kline et al. (1986), Taylor and Bender (1991), Fink and Kohler (2011). Examples for the variability of the strength properties are Taylor and Bender (1991), Lam and Varoglu (1991a, b), Czmoch et al. (1991), Isaksson (1999), Kohler et al. (2013). In the above mentioned models, first the strength and/or stiffness properties of timber board sections are measured. Afterwards, probabilistic models are developed to describe those measured material properties. The drawback of such an approach is that the experimental investigations are very time consuming. Therefore, the amount of tested specimens is relatively small and thus the probabilistic models are associated with large statistical uncertainties. Furthermore, the developed models can only be used to describe the material properties of the investigated strength grades, dimensions, growing regions, and so on.

In this paper, a model is presented where, instead of strength and stiffness properties, the so-called strength and stiffness related indicators are described probabilisticallyhere the dynamic modulus of elasticity based on eigenfrequency measurement $\left(E_{\mathrm{dyn}, \mathrm{F}}\right)$ and the total knot area ratio (tKAR-value). Afterwards, the material properties of the timber board sections are estimated with the material model presented in Fink and Kohler (2014). One advantage of this approach is that strength and stiffness related indicators are easier to measure. Thus, the model can be extended for different strength grades or different growth regions with a comparable small amount of additional 
effort; for instance it could be based on strength and stiffness related indicators measured automatically during the grading process. A similar approach is presented in Colling (1990); Blaß et al. (2008) to model the material properties of the lamellas within glued laminated timber. There, the dry density and a knot ratio were used as strength and stiffness related indicators.

The presented probabilistic approach describes the growth characteristic of timber boards for two different strength grades. It includes (a) the geometrical setup of timber boards-position of knot clusters, and (b) a hierarchical representation of two strength and stiffness related indicators $-E_{\mathrm{dyn}, \mathrm{F}}$ and tKAR-value.

\section{Material and methods}

The investigation was conducted in the laboratory at ETH Zurich. The associated experiments were part of a research project for the non-destructive evaluation of the modulus of elasticity within timber boards (Fink and Kohler 2012). For this purpose, the efficiency of different strength and stiffness related indicators was investigated. In this paper only the investigations essential for the probabilistic model are described: (a) the estimation of dynamic modulus of elasticity based on eigenfrequency measurement $\left(E_{\mathrm{dyn}, \mathrm{F}}\right)$ - to describe the mean material properties of the timber boards, and (b) the total knot area ratio (tKAR-value) - to describe the lengthwise variability within timber boards. The two indicators have been established to be most efficient for the prediction of the tensile strength and the tensile stiffness; see Fink (2014) for detailed description.

\subsection{Specimens}

The investigation took place on two samples, each of 200 specimens; the species was Norway spruce (Picea abies) from southern Germany. The dimensions of the timber boards were $126 \times 44 \times 4000 \mathrm{~mm}^{3}$. All timber boards were graded into the strength grades L25 and L40. According to the European standard EN 14081-4 (2009) these strength grades require a minimum characteristic tensile capacity of 14.5 and $26.0 \mathrm{MPa}$, respectively. The timber boards were graded with the GoldenEye-706 grading device manufactured by MiCROTEC (Brixen, IT) (Giudiceandrea 2005).

\subsection{Dynamic modulus of elasticity: $E_{\mathrm{dyn}, \mathrm{F}}$}

For the prediction of the mean material properties the dynamic modulus of elasticity based on eigenfrequency
$\left(E_{\mathrm{dyn}, \mathrm{F}}\right)$ was identified for all 400 specimens. For this purpose, the eigenfrequency $f_{0}$, the length $l$, the density $\rho$ (estimated through dimension and mass), and the moisture content (using electrical resistance measurement) were measured. Based on the measurements $E_{\mathrm{dyn}, \mathrm{F}}$ was calculated according to Eq. (1) (see e.g. Görlacher 1984, 1990). Afterwards, the assessed values were corrected to a reference moisture content according to EN 384 (2004).

$$
E_{\mathrm{dyn}, \mathrm{F}}=\left(2 l f_{0}\right)^{2} \rho
$$

\subsection{Total knot area ratio-tKAR}

To consider the lengthwise variability (within-member variability) of the timber boards the position and dimension of the knots were measured. For this reason, each knot with a diameter larger than $10 \mathrm{~mm}$ was assessed and recorded. Based on the knot measurement the tKAR-value was identified (every knot in the timber board is assumed to have cylindrical shape). The tKARvalue is defined as the ratio between the projected knot area within a length of $150 \mathrm{~mm}$ and the cross sectional area (e.g. Isaksson 1999).

\section{Geometrical setup}

\subsection{Definition of weak section}

The positions of weak sections (denoted WS) are extracted from the knot measurements. In order to do that, a definition of a WS is established. In the presented work, a threshold tKAR $=0.1$ is introduced; i.e. knot clusters with

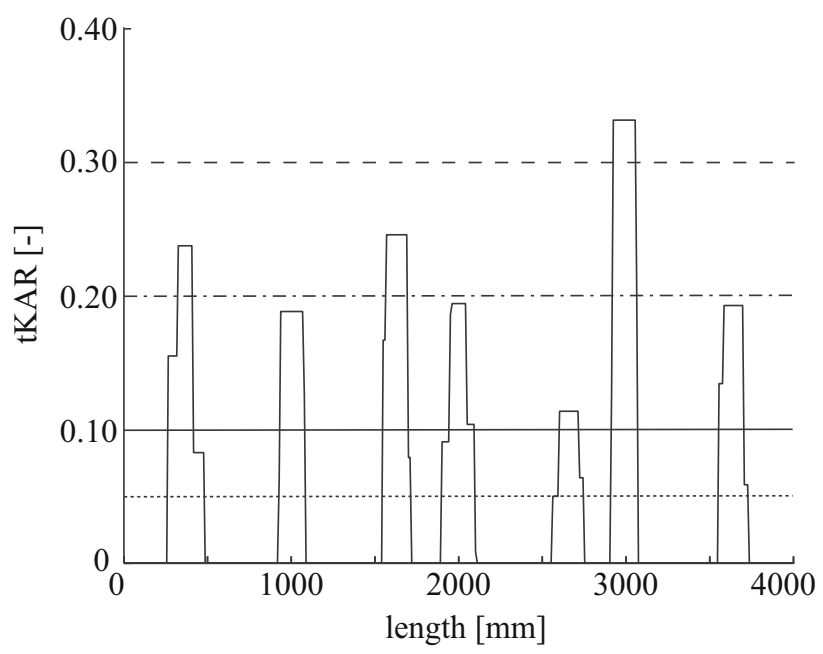

Fig. 1 KAR-value distribution of one timber board 
tKAR $\geq 0.1$ are defined as WS, whereas knot clusters with tKAR $<0.1$ are neglected. Using this threshold the majority of the knot clusters are identified as WS, especially knot clusters having a large tKAR-value. Fig. 1 illustrates the principle: Choosing a threshold tKAR $=0.3$ (dashed line) only 1 WS is identified. It is obvious that with a smaller threshold more WS are identified; e.g. tKAR $=0.2$ (dashed-dotted line) leads to $3 \mathrm{WS}$, tKAR $=0.1$ (solid line) to $7 \mathrm{WS}$, and tKAR $=0.05$ (dotted line) to $7 \mathrm{WS}$. In the presented work $(\mathrm{tKAR}=0.1)$, altogether $2870 \mathrm{WS}$ (L25: 1416 WS, L40: 1454 WS) are identified. In accordance with the definition of the tKAR-value a constant WS-length $l_{\mathrm{WS}}=150 \mathrm{~mm}$ is assumed.

\subsection{Distance between weak sections}

The distance between WS (denoted $d$ ) is defined as the distance between the mid-points of two adjacent WS. The occurrence of knot clusters in the longitudinal direction of the trunk of a growing tree might be represented by a Poisson process and therefore the distances between knot clusters would be exponentially distributed. When sawing out timber boards not every knot cluster might appear in every particular timber board. As a result, the distance between knot clusters that appear in the boards might be best represented by the Gamma distribution, which corresponds to the distribution of the distance between the $i$ th and $i+k$ th occurrence of a Poisson process. The Gamma distribution is generalized when $k$ is not an integer.

According to the definition a WS has a constant length $\left(l_{\mathrm{WS}}=150 \mathrm{~mm}\right)$. Thus the minimal distance between two adjacent WS is $d_{\min }=150 \mathrm{~mm}$. As a result, a shifted Gamma distribution is used to describe $d$ (Fig. 2):

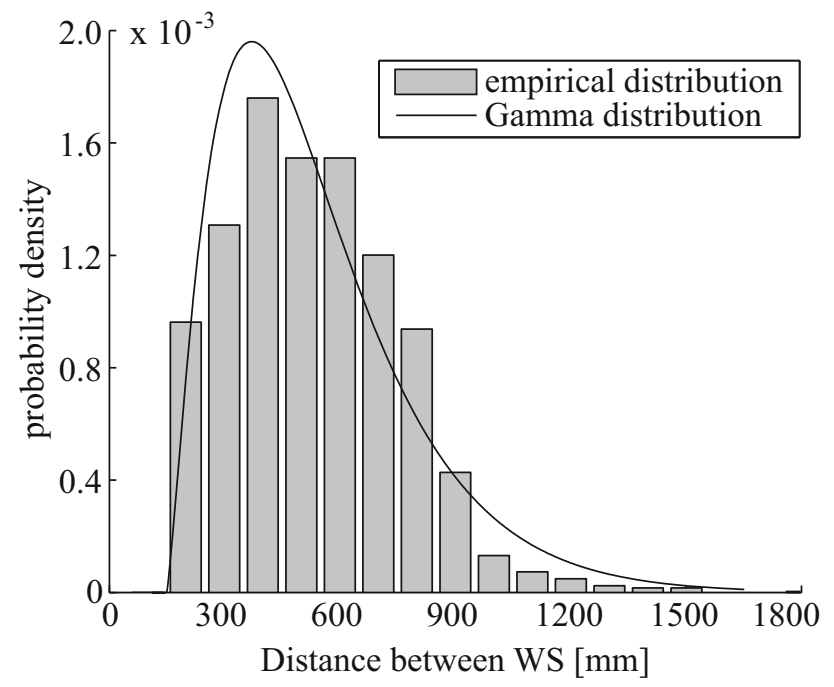

Fig. 2 Probability density function of the distance between the WS (d) using a shifted Gamma distribution and the corresponding histogram
$f(d)=\frac{v\left(v\left(d-l_{\mathrm{WS}}\right)\right)^{k-1}}{\Gamma(k)} e^{-v\left(d-l_{\mathrm{Ws}}\right)}+l_{\mathrm{WS}}$

$l_{\mathrm{WS}} \leq d \leq \infty$

The parameters $k, v$ of the Gamma distribution, their correlation $\rho(k, v)$ and their uncertainties are estimated, taking into account all detected distances between WS in the 400 investigated timber boards; they are summarised in Table 1. The parameters correspond to expected values $\mathrm{E}\left(d_{\mathrm{L} 25}\right)=537 \mathrm{~mm}$ and $\mathrm{E}\left(d_{\mathrm{L} 40}\right)=521 \mathrm{~mm}$, and standard deviations $\sigma\left(d_{\mathrm{L} 25}\right)=253 \mathrm{~mm}$ and $\sigma\left(d_{\mathrm{L} 40}\right)=240 \mathrm{~mm}$. Thus, only a marginal difference between the two strength grades is identified: the difference between the expected values is about $16 \mathrm{~mm}$. Consequently, it will not be distinguished between the two strength grades when modelling $d$ : Taking into account both strength grades: $\mathrm{E}(d)=529 \mathrm{~mm}$ and $\sigma(d)=246 \mathrm{~mm}$.

The small coefficients of variation of the two parameters $k$ and $v$ indicate that the number of specimens is apparently large enough for an efficient parameter estimation. However, the estimated parameters are highly related to the definition of WS (see e.g. Isaksson 1999; Fink and Kohler 2012). As mentioned above, a WS is defined as a section with $\mathrm{tKAR} \geq 0.1$. When choosing a lower tKAR-value more WS would be detected and thus the distance between them would decrease; e.g. $\mathrm{tKAR}=0.05$ leads to $\mathrm{E}(d)=485 \mathrm{~mm}$ and $\sigma(d)=215 \mathrm{~mm}$.

The estimated values can be compared with former studies (e.g. Isaksson 1999; Colling and Dinort 1987). Isaksson also described $d$ with the Gamma distribution and identified an expected value of $494 \mathrm{~mm}$ with a standard deviation of $310 \mathrm{~mm}$. The results of this study are similar although the timber has different origins (the timber of the present study is grown in the southern part of Germany, whereas the timber in the study of Isaksson is grown in southern Sweden), and a different definition of the WS (Isaksson defined a WS as a section with tKAR $\geq 0.5 \cdot \mathrm{tKAR}_{\max } ; \mathrm{tKAR}_{\max }$ is the largest tKAR-value

Table 1 Compilation of the model for the probabilistic representation of timber: Expected value, COV in brackets

\begin{tabular}{llll}
\hline Model & Parameter & \multicolumn{2}{l}{ Strength grade } \\
\cline { 3 - 4 } & & \multicolumn{2}{l}{ L25 40} \\
\hline$d$ & $k$ & $2.37(0.0158)$ \\
& $v$ & $0.0063(0.0132)$ \\
& $\rho(k, v)$ & 0.671 & \\
tKAR & $\mu$ & $-1.50(0.0067)$ & $-1.70(0.0050)$ \\
& $\sigma_{\tau}$ & $0.184(0.050)$ & $0.171(0.050)$ \\
& $\sigma_{\epsilon}$ & $0.335(0.019)$ & $0.281(0.019)$ \\
$E_{\text {dyn }, \mathrm{F}}$ & $\mu$ & $9.35(0.0009)$ & $9.68(0.0006)$ \\
& $\sigma_{\tau}$ & $0.124(0.050)$ & $0.0877(0.050)$ \\
\hline
\end{tabular}


within a timber board). Colling and Dinort investigated $d$ on timber boards from Germany, Austria, and Scandinavia. There, a mean distance between the WS of 450-500 mm was found. Furthermore, Colling and Dinort also did not identify significant differences of $d$ between different strength grades.

\section{Strength and stiffness related indicators}

\section{1 tKAR-value}

According to definition, the tKAR-value of every timber board section has to be within the interval $[0,1]$. Through the grading process an upper limit $\mathrm{tKAR}_{\text {limit }}$ could be introduced; e.g. visually graded timber is usually regulated through upper limits for permissible knot dimensions [e.g. DIN 4074-1 (2008), SIA 265-1 (2009)]. It is obvious that $\mathrm{tKAR}_{\text {limit }}$ is smaller for higher strength grades. However, it has to be considered that in reality the grading process is not perfect; i.e. there is a certain probability that the tKARvalue exceeds the defined threshold. Furthermore, it has to be considered that the presented model is baesed on timber boards graded by the Goldeneye-706 grading device. Thus, for this timber boards no upper limit of the tKAR-value exists. As a result, in the present study no upper limit through the grading process is introduced: $\mathrm{tKAR}_{\text {limit }}=1$.

To describe the tKAR-value of a WS, the Lognormal distribution with a truncated upper tail $\left(\mathrm{tKAR}_{\text {limit }}=1\right)$ was used: $f_{X}^{*}(x)$ in Eq. (3). Here, $f_{X}(x)$ is the probability density function of the Lognormal distribution, and $F_{X}\left(\mathrm{tKAR}_{\text {limit }}\right)$ is the cumulative distribution function up to the upper limit, which is the area of the probability density function for the interval $\left[0, \mathrm{tKAR}_{\text {limit }}\right]$. The truncated Lognormal distribution seems to be suitable regarding (a) the flat tail within the area of small tKAR-values (knot clusters with tKAR $<0.1$ are not considered as WS), (b) the flat tail within the area of large tKAR-values (according to the grading criteria the probability of large tKAR-values is rather small), and (c) the truncated upper tail $\mathrm{tKAR}_{\text {limit }}$ (Fig. 3). The area of the truncated tail of the density function for the strength grades L25 and L40 are $f_{X}(x \mid X \geq 1)=1-F_{X}\left(\mathrm{tKAR}_{\text {limit }}=1\right)=$ $4 \cdot 10^{-5}$ and $8 \cdot 10^{-8}$, respectively. Thus, its influence is rather small. However, it is a threshold that cannot be exceed by definition.

$f_{X}^{*}(x)=\frac{f_{X}(x)}{F_{X}\left(\mathrm{tKAR}_{\text {limit }}\right)}$

Assuming a truncated Lognormal distribution with $\mathrm{tKAR}_{\text {limit }}=1$, the expected values of tKAR are $\mathrm{E}\left(\mathrm{tKAR}_{\mathrm{L} 25}\right)=0.240$ and $\mathrm{E}\left(\mathrm{tKAR}_{\mathrm{L} 40}\right)=0.192$, with standard deviations $\sigma\left(\mathrm{tKAR}_{\mathrm{L} 25}\right)=0.095$ and $\sigma\left(\mathrm{tKAR}_{\mathrm{L} 40}\right)=$ 0.064. Thus, the tKAR-values of WS within timber boards
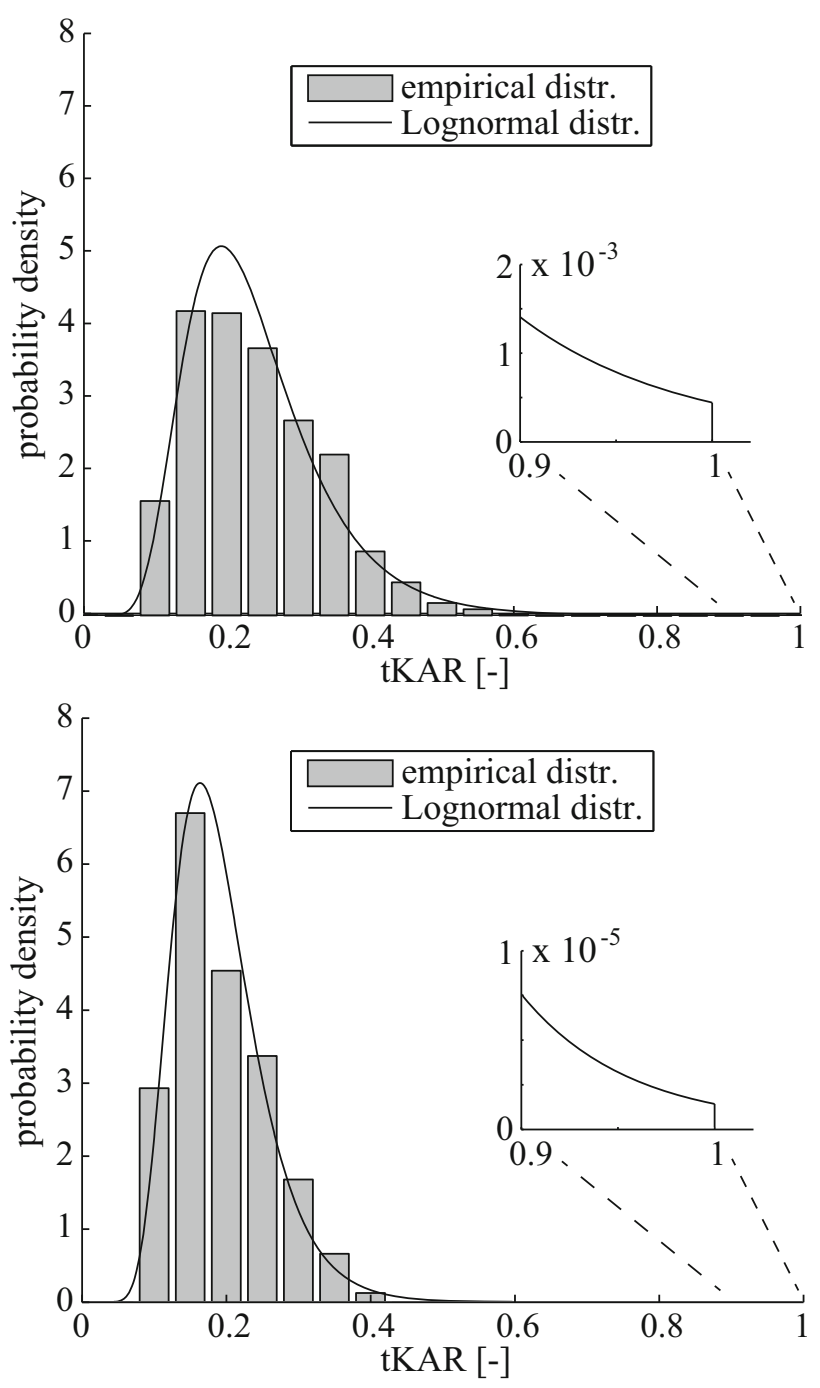

Fig. 3 Probability density function of the tKAR-value using a truncated Lognormal distribution and the corresponding histogram: (top) strength grade L25, (bottom) strength grade L40

of the lower strength grade are significantly larger (as it was foreseeable) and show a larger variation. Compared to former studies, here the mean tKAR is relatively large; e.g. Colling and Dinort (1987) identified a mean tKAR of 0.15 0.20 (considering only knot clusters with $\mathrm{TKAR} \geq 0.1$ ). The reason for the increase might be the different grading criteria of the two studies. Further it has to be considered that the time between the studies was more than 25 years and thus the requirements to the forest and the sawmill industry have changed. This might have an influence on the quality of sawn timber (Blaß et al. 2008).

The tKAR-value is described by a hierarchical model with two hierarchical levels (Kersken-Bradley and Rackwitz 1991; Köhler and Faber 2004), namely the meso- and micro-scale. The meso-scale describes the variability of a single timber board within a sample of timber boards. The micro-scale describes the variability 
within one timber board. The hierarchical model is given in Eq. (4). Here, $\tau$ is introduced to describe the meso-scale variability and $\epsilon$ to describe the micro-scale variability. To consider $\mathrm{KKAR}_{\text {limit }}$, the combined realization of large $\tau$ and large $\epsilon$ is prevented.

$$
\begin{aligned}
& \operatorname{tKAR}_{i j}=\exp \left(\mu+\tau_{\mathrm{i}}+\epsilon_{i j}\right) \\
& \text { with } \tau_{i}+\epsilon_{i j} \leq \ln \left(\mathrm{tKAR}_{\text {limit }}\right)-\mu
\end{aligned}
$$

where

$\operatorname{tKAR}_{i j} \quad$ is the tKAR of the WS $j$ in a board $i . \mathrm{THAR}_{i j}$ is a truncated Lognormal random variable

$\mu \quad$ is the logarithmic mean tKAR of all WS within a sample of boards. $\mu$ is considered to be deterministic

$\tau_{i} \quad$ is the difference between the logarithmic mean tKAR of all WS within one board $i$ and $\mu . \tau_{i}$ is represented by a Normal distributed random variable $\tau_{i} \sim N\left(0, \sigma_{\tau}\right)$

$\epsilon_{i j} \quad$ is the difference between WS $j$ in a board $i$ mean tKAR of all WS within one board $i\left(\mu+\tau_{i}\right) . \epsilon_{i j}$ is represented by a Normal distributed random variable $\epsilon_{i j} \sim N\left(0, \sigma_{\epsilon}\right)$

The parameters of the distribution function and the associated uncertainties are estimated using maximum likelihood method (MLM); see e.g. Benjamin and Cornell (1970). The basic principle of the MLM is to find the parameters of the chosen distribution function which most likely reflect the data sample. The parameters of the distribution function are estimated by solving the optimisation problem given in Eq. (6). The likelihood $L(\boldsymbol{\theta} \mid \hat{\mathbf{x}})$ of the observed data is defined according to Eq. (5), where $\boldsymbol{\theta}$ represents the parameters, $f_{X}$ is the density function of the random variable $\mathrm{X}$, and $\hat{x}$ the measured values of the data sample.

$$
\begin{aligned}
& L(\boldsymbol{\theta} \mid \hat{\mathbf{x}})=\prod_{i=0}^{n} f_{X}\left(\hat{x}_{i} \mid \boldsymbol{\theta}\right) \\
& \min _{\boldsymbol{\theta}}(-L(\boldsymbol{\theta} \mid \hat{\mathbf{x}}))
\end{aligned}
$$

The uncertainties of the MLM estimators can be expressed with covariance matrix $\mathbf{C}_{\Theta \Theta}$, where the diagonals are the variances of the estimated distribution parameters and the other elements are the covariances between the parameters. The covariance matrix $\mathbf{C}_{\Theta \Theta}$ is defined as the inverse of the Fisher information matrix $\mathbf{H}$. The components of $\mathbf{H}$ are determined by the second order partial derivatives of the log-likelihood function; see e.g. Faber (2012).

$$
\begin{aligned}
& \mathbf{C}_{\Theta \Theta}=\mathbf{H}^{-\mathbf{1}} \\
& H_{i j}=-\left.\frac{\partial^{2} l(\boldsymbol{\theta} \mid \hat{\boldsymbol{x}})}{\partial \theta_{i} \partial \theta_{j}}\right|_{\boldsymbol{\theta}=\boldsymbol{\theta}^{*}}
\end{aligned}
$$

The parameters of Eq. (4) and their uncertainties, expressed through the coefficient of variation (denoted COV), are summarised in Table 1. According to the large amount of WS (2870), the statistical uncertainties of the estimated parameters are rather small, especially for $\mu$ and $\epsilon$. The parameter $\tau$ is estimated on a smaller number of data (200 specimens per strength grade), thus the uncertainties are larger.

\subsection{Dynamic modulus of elasticity}

The dynamic modulus of elasticity based on eigenfrequency $E_{\mathrm{dyn}, \mathrm{F}}$ is also described by a hierarchical model. $E_{\mathrm{dyn}, \mathrm{F}}$ represents a mean value over the entire timber board. Thereby, only the first hierarchical level (mesoscale), which describes the variability of a single timber board within a sample of timber boards, is used (Eq. 9). $E_{\text {dyn,F }}$ is assumed to be Lognormal distributed, as it is recommended in the Probabilistic Model Code of the Joint Committee on Structural Safety (JCSS 2006); for more information see also Köhler et al. (2007). The Lognormal distribution is suitable, since (a) the flat tail within the area of small and large eigenfrequencies (according to the grading criteria the probability of small and large $E_{\mathrm{dyn}, \mathrm{F}}$ is rather small), and (b) negative realisations of $E_{\mathrm{dyn}, \mathrm{F}}$ are prevented, which is of particular importance for the simulation of materials having a large variability such as timber (see Fig. 4).

$$
E_{\mathrm{dyn}, \mathrm{F}, i}=\exp \left(\mu+\tau_{i}\right)
$$

where

$E_{\mathrm{dyn}, \mathrm{F}, i}$ is the $E_{\mathrm{dyn}, \mathrm{F}}$ of the board $i . E_{\mathrm{dyn}, \mathrm{F}, i}$ is a Lognormal random variable

$\mu \quad$ is the logarithmic mean of all $E_{\mathrm{dyn}, \mathrm{F}}$ within a sample of boards. $\mu$ is considered to be deterministic

$\tau_{i} \quad$ is the difference between the logarithmic mean of $E_{\mathrm{dyn}, \mathrm{F}}$ in the board $i$ and $\mu . \tau_{i}$ is represented by a Normal distributed random variable $\tau_{i} \sim N\left(0, \sigma_{\tau}\right)$

The results are summarised in Table 1 . The estimated parameters correspond to expected values $\mathrm{E}\left(E_{\mathrm{dyn}, \mathrm{F}, \mathrm{L} 25}\right)=$ $11630 \mathrm{MPa}$ and $\mathrm{E}\left(E_{\mathrm{dyn}, \mathrm{F}, \mathrm{L} 40}\right)=15980 \mathrm{MPa}$, and standard deviations $\sigma\left(E_{\mathrm{dyn}, \mathrm{F}, \mathrm{L} 25}\right)=1450 \mathrm{MPa}$ and $\sigma\left(E_{\mathrm{dyn}, \mathrm{F}, \mathrm{L} 40}\right)=$ $1400 \mathrm{MPa}$. Even the expected value of the upper strength grade is significantly larger $(\sim 35 \%)$ it seems that the standard deviation is almost unaffected.

\subsection{Correlation between the parameters}

In addition to the three parameters $\left(d, E_{\mathrm{dyn}, \mathrm{F}}\right.$ and tKAR), their correlations are analysed with particular focus on the 

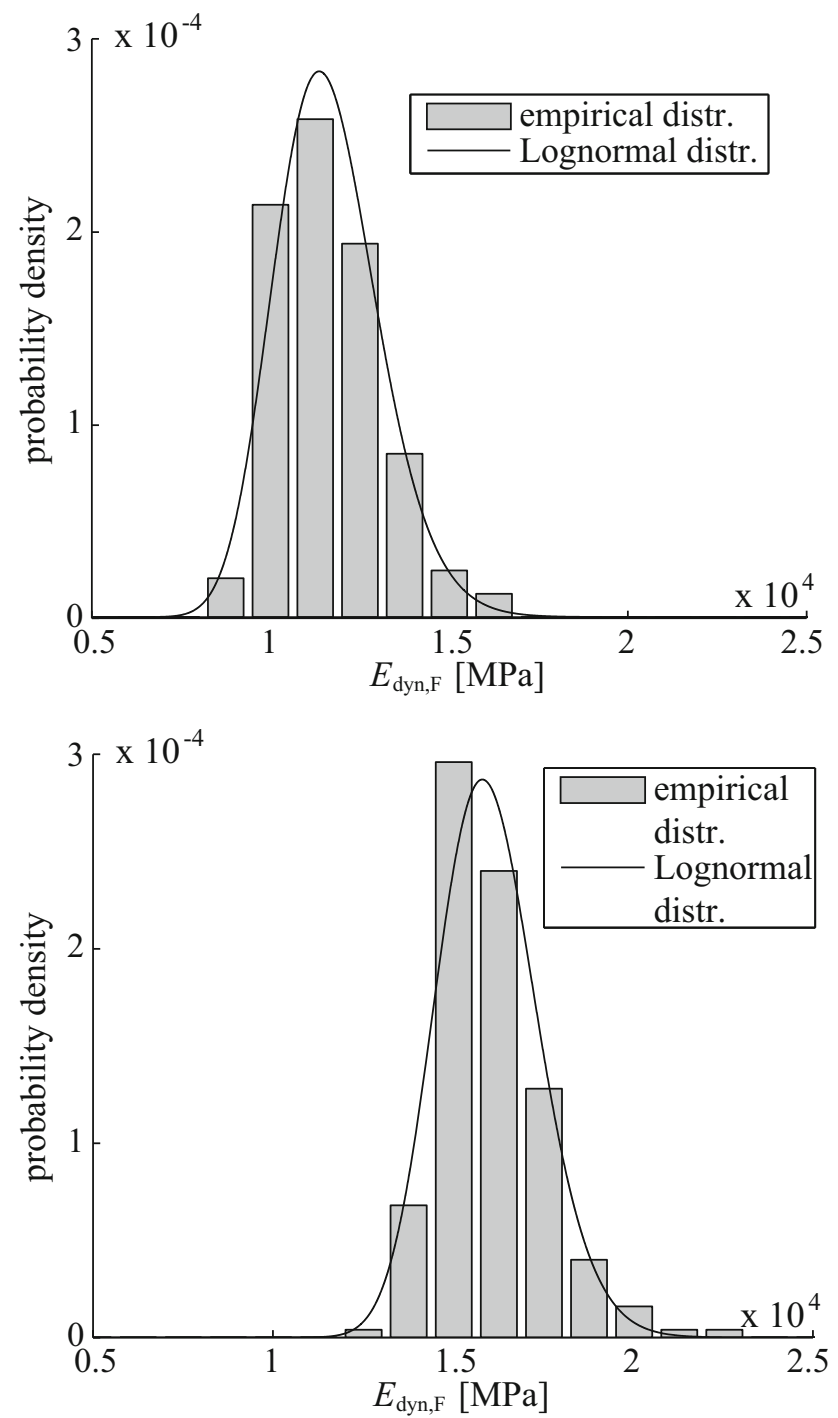

Fig. 4 Probability density function of the dynamic modulus of elasticity $E_{\mathrm{dyn}, \mathrm{F}}$ using a Lognormal distribution and the corresponding histogram: (top) strength grade L25, (bottom) strength grade L40

correlations between timber boards of the same strength grade. That includes correlation between the following three parameters:

- mean tKAR in a timber board (referred to as $\mathrm{tKAR}_{i}$ )

- dynamic modulus of elasticity based on eigenfrequency measurement $E_{\mathrm{dyn}, \mathrm{F}}$

- mean distance between the WS within one timber board (referred to as $d_{i}$ )

The estimated correlations are summarised in Table 2 . Between the $\operatorname{tKAR}_{i}$ and $E_{\mathrm{dyn}, \mathrm{F}}$ a negative correlation is identified (see Fig. 5). This is plausible due to the fact that timber boards of higher strength grades have a larger mean stiffness and less and/or smaller knots. However, within one strength grade the correlations are small $|\rho| \leq 0.182$.
Table 2 Correlation between the estimated parameters

\begin{tabular}{lrl}
\hline Correlations & \multicolumn{1}{c}{ L25 } & L40 \\
\hline$\rho\left(\mathrm{tKAR}_{i}, E_{\mathrm{dyn}, \mathrm{F}}\right)$ & -0.182 & -0.085 \\
$\rho\left(\mathrm{tKAR}_{i}, d_{i}\right)$ & 0.221 & -0.159 \\
$\rho\left(E_{\mathrm{dyn}, \mathrm{F}}, d_{i}\right)$ & -0.093 & -0.062 \\
\hline
\end{tabular}

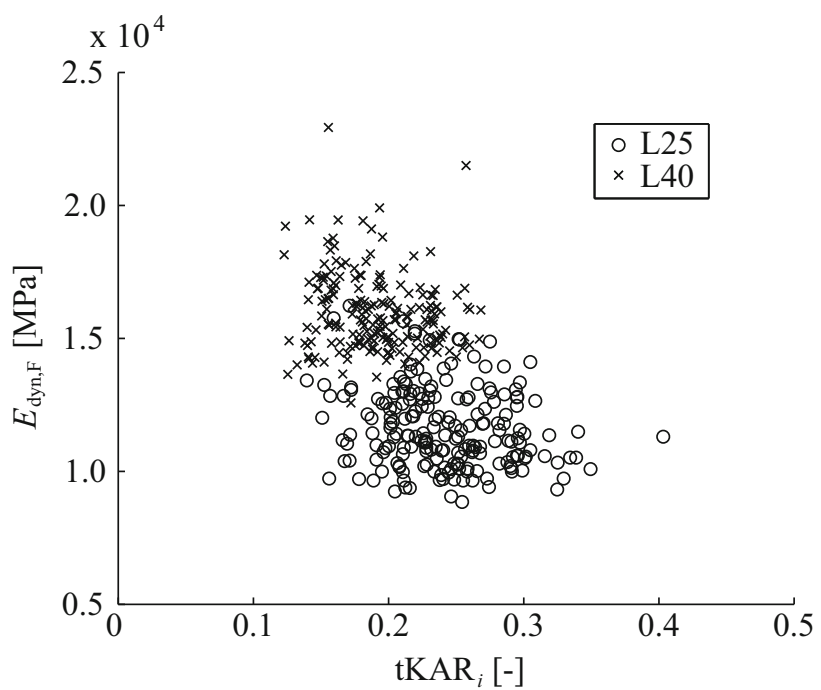

Fig. 5 Correlation between $E_{\mathrm{dyn}, \mathrm{F}}$ and $\mathrm{tKAR}_{i}$

The low correlations between $d_{i}$ and the other two parameters $\left(\mathrm{tKAR}_{i}\right.$ and $\left.E_{\mathrm{dyn}, \mathrm{F}}\right)$ are also plausible, as a result that the distance between WS is only marginally influenced by the strength grade. At this point it has to be mentioned that the low correlations might be a result of the sample size (200 timber boards per strength grade). However, due to the low correlations they are not considered within the model.

\section{Relation between parameters and material properties}

Using the probabilistic model introduced before it is possible to simulate timber boards, or more precisely their strength and stiffness related indicators. However, for modelling the tensile strength and tensile stiffness material models are necessary. In this paper the material properties are estimated using the material model developed by Fink and Kohler (2014). Using this model the tensile strength and stiffness of WS within timber boards can be estimated by using a linear regression model; Eq. (10). Here $Y$ represents the tensile strength of WS (denoted $f_{\mathrm{t}, \mathrm{WS}}$ ) or the tensile stiffness of WS (denoted $E_{\mathrm{t}, \mathrm{WS}}$ ), and $\beta_{i}$ are the regression parameter. The parameter for Eq. (10) are summarized in Table 3

$\ln (Y)=\beta_{0}+\beta_{1} \cdot E_{\mathrm{dyn}, \mathrm{F}}+\beta_{2} \cdot \mathrm{tKAR}+\varepsilon$ 
Table 3 Parameter for the models to predict $E_{\mathrm{t}, \mathrm{Ws}}$ and $f_{\mathrm{t}, \mathrm{Ws}}$ (from Fink and Kohler 2014)

\begin{tabular}{|c|c|c|c|c|c|c|}
\hline \multirow[t]{2}{*}{ Parameter } & \multicolumn{3}{|c|}{ Stiffness model $E_{\mathrm{t}, \mathrm{WS}}$} & \multicolumn{3}{|c|}{ Strength model $f_{\mathrm{t}, \mathrm{ws}}$} \\
\hline & Expected value & $\mathrm{COV}$ & Correlation & Expected value & $\mathrm{COV}$ & Correlation \\
\hline$\beta_{0}$ & 8.41 & 0.0027 & $\rho\left(\beta_{0}, \beta_{1}\right)=-0.922$ & 2.96 & 0.0067 & $\rho\left(\beta_{0}, \beta_{1}\right)=-0.922$ \\
\hline$\beta_{1}$ & $7.69 \cdot 10^{-5}$ & 0.019 & $\rho\left(\beta_{0}, \beta_{2}\right)=-0.564$ & $8.50 \cdot 10^{-5}$ & 0.017 & $\rho\left(\beta_{0}, \beta_{2}\right)=-0.596$ \\
\hline$\beta_{2}$ & $-9.02 \cdot 10^{-1}$ & 0.040 & $\rho\left(\beta_{1}, \beta_{2}\right)=0.234$ & -2.22 & 0.016 & $\rho\left(\beta_{1}, \beta_{2}\right)=0.274$ \\
\hline$\sigma_{\varepsilon}$ & $1.00 \cdot 10^{-1}$ & 0.024 & $\rho\left(\beta_{i}, \sigma_{\varepsilon}\right) \approx 0$ & $1.50 \cdot 10^{-1}$ & 0.014 & $\rho\left(\beta_{i}, \sigma_{\varepsilon}\right) \approx 0$ \\
\hline
\end{tabular}

The mentioned material model was developed based on the measured tensile stiffness of 864 knot clusters, and the measured tensile capacity of 450 timber boards containing 2577 knot clusters. For the strength model the censored regression analysis was used.

The present model can also be used to predict the tensile strength and stiffness of knot free timber boards sections (referred to as clear wood sections-CWS, tKAR $=0$ ). However, according to Fink and Kohler (2014) both, the tensile strength and tensile stiffness, will be slightly underestimated $(\approx 3 \%)$.

\subsection{Finger joint connections}

Using the presented models, it is also possible to estimate the tensile strength and stiffness of finger joint connections (FJ); denoted $f_{\mathrm{t}, \mathrm{j}}$ and $E_{\mathrm{t}, \mathrm{j}}$, respectively. Therefore, the corresponding literature has to be taken into account. The stiffness properties of FJ were analysed by Samson (1985), Heimeshoff and Glos (1980) for bending and Ehlbeck et al. (1985) for tension. All studies showed no significant difference to the stiffness properties of CWS. Thus, $E_{\mathrm{t}, \mathrm{j}}$ is assumed to be the mean of the two adjacent CWS (denoted $E_{\mathrm{t}, \mathrm{CWS}, i}$ ):

$E_{\mathrm{t}, \mathrm{j}}=\frac{1}{2} \sum_{i=1}^{2} E_{\mathrm{t}, \mathrm{CWS}, i}$

To model the tensile strength of finger joints $f_{\mathrm{t}, \mathrm{j}}$, which is one of the most important parameters to model the mechanical performance of glued laminated timber, a very simple and plausible approach is chosen: it is assumed that $f_{\mathrm{t}, \mathrm{j}}$ is equal to $f_{\mathrm{t}, \mathrm{Ws}}$ having a specific tKAR-value (Eq. 12). This approach has already been mentioned in other studies (e.g. Pellicane et al. 1987; Colling 1990). Based on the mentioned literature and the experimental experience of the research group at ETH Zurich, $0.2 \leq \mathrm{tKAR} \leq 0.3$ seems to be realistic.

$$
\begin{aligned}
f_{\mathrm{t}, \mathrm{j}} & =\min _{i=1,2}\left\{f_{\mathrm{t}, \mathrm{WS}, i} \mid \mathrm{tKAR}\right\} \\
& =\beta_{0}+\beta_{1} \cdot \min _{i=1,2}\left\{E_{\mathrm{dyn}, \mathrm{F}, i}\right\}+\beta_{2} \cdot \mathrm{tKAR}+\varepsilon
\end{aligned}
$$

In order to verify the introduced material model it is compared with the model presented in Blaß et al. (2008).

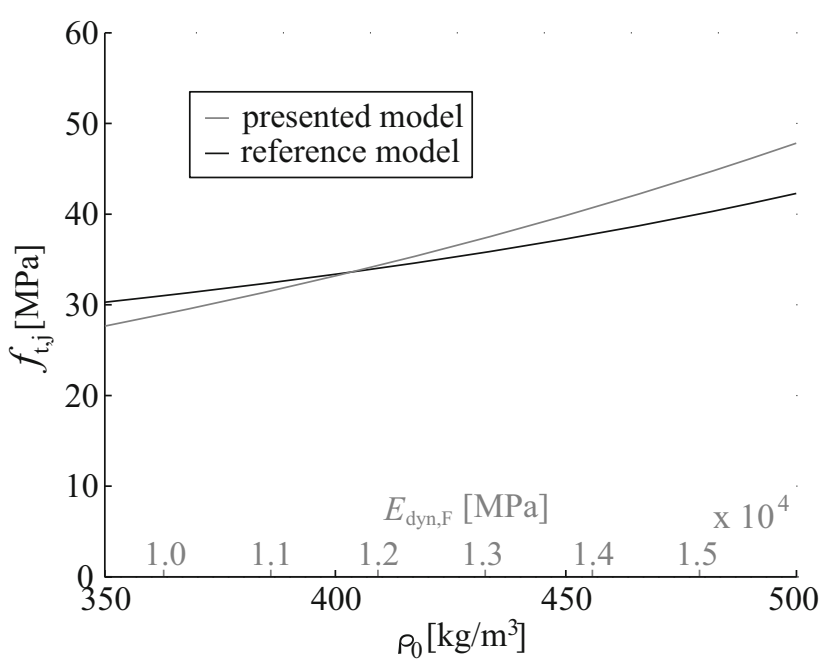

Fig. 6 Verification of the model to predict the tensile capacity of finger joint connections $f_{\mathrm{t}, \mathrm{j}}$

The tensile strength of the FJ was assumed to be the tensile strength of a WS with tKAR $=0.2$. In Blaß et al. (2008) $f_{\mathrm{t}, \mathrm{j}}$ is modelled as a function of the dry density $\rho_{0}$, here it is a function of $E_{\mathrm{dyn}, \mathrm{F}}$. In both models $f_{\mathrm{t}, \mathrm{j}}$ is estimated based on the global indicator ( $\rho_{0}$ or $E_{\mathrm{dyn}, \mathrm{F}}$ ) from the weaker of the two associated timber boards. To describe the interaction between the two indicators, a linear regression model with the corresponding expression for the expected value of $E_{\text {dyn,F }}$ was used: $\mathrm{E}\left[E_{\text {dyn,F }}\right]=-5.6 \cdot 10^{3}+43 \rho_{0}$. The regression model is developed based on 950 investigated timber boards (Fink 2014). In Fig. 6, the estimated $f_{\mathrm{t}, \mathrm{j}}$ for typical dry densities $350 \leq \rho_{0} \leq 500 \mathrm{~kg} / \mathrm{m}^{3}$ are illustrated. In the presented model, the influence of the stiffness related indicator is larger; i.e. the curve is steeper. However, it seems that if tKAR $=0.20$ is used, the present model is similar to the reference model, in particular for timber boards with a small $\rho_{0}$.

\subsection{Model uncertainty}

It is obvious that the prediction of material properties is associated with model uncertainties. The model uncertainties, expressed through the error term $\varepsilon$, were identified 
for the tensile strength and stiffness model. However, using censored regression analysis to estimate the parameter the model uncertainties were underestimated. To compensate that, a larger standard deviation of the error term $\sigma_{\varepsilon}=0.2$ is assumed; see also Fink (2014).

To consider the correlation of the material properties in each particular member, the error term $\varepsilon$ was separated into two parts: one part for the uncertainty of the mean material properties (constant within one timber board-denoted $\varepsilon_{1}$ ) and the other part for the uncertainty of the strength/stiffness reduction of each particular WS (denoted $\varepsilon_{2}$ ). A ratio between the two parts of $\varepsilon_{1}: \varepsilon_{2}=2: 1$ is chosen in accordance with the investigations of Colling (1990).

Furthermore, the correlation between the strength and stiffness properties has to be considered. Therefore, a correlation between strength and stiffness related error terms $\rho=0.8$ is assumed. To model FJ the same model uncertainties are assumed as for WS.

\section{Application-modelling of timber boards and finger joint connections}

\subsection{Timber boards}

Applying the probabilistic model and the material model, it is possible to model timber boards, or rather the tensile strength and the tensile stiffness within timber boards. The procedure is as follows:

1. Modelling the parameters $E_{\mathrm{dyn}, \mathrm{F}}, d$, and tKAR:

- Modelling timber boards with a specific $E_{\mathrm{dyn}, \mathrm{F}}-$ Eq. (9)

- Modelling the position and the tKAR-value of each particular WS-Eqs. (2), (4)

2. Allocate the strength and stiffness properties:

- Estimation of the tensile strength and stiffness of CWS and WS-Eq. (10)

- Modelling the uncertainties $\varepsilon_{1}$ and $\varepsilon_{2}$

Within one particular timber board the global indicator $E_{\mathrm{dyn}, \mathrm{F}}$ is constant. Thus, and because of the hierarchical model of tKAR, the within-member correlation is considered; i.e. the correlation of board sections within one timber board. Both material properties (tensile strength and tensile stiffness) of one particular timber board section, are calculated with the same input parameters $\left(E_{\mathrm{dyn}, \mathrm{F}}\right.$ and tKAR). Thus, the correlation between tensile strength and tensile stiffness is automatically considered.

In the following paragraphs, the tensile strength and stiffness properties of the simulated timber boards are estimated. For this purpose, timber boards with a length $l=1620 \mathrm{~mm}$ are simulated. The chosen length corresponds to the required testing length for typical timber boards $b \times t_{1}=180 \times 40 \mathrm{~mm}^{2}$, according to EN 4082003 ; here $b$ is the board width and $t_{1}$ is the board thickness.

Based on a sufficient amount of simulated timber boards several parameters of the material properties, such as the characteristic value of the tensile strength $f_{\mathrm{t}, \mathrm{k}}$ or the mean stiffness $E_{\mathrm{t}, \text { mean }}$, can be calculated. In the present example $n=10^{4}$ timber boards are simulated.

\subsubsection{Tensile strength}

To estimate the tensile strength $f_{\mathrm{t}}$ of the simulated timber boards the following failure criterion is chosen: the tensile strength of a timber board is assumed to be the tensile strength of the weakest section of the timber board. Taking into account $f_{\mathrm{t}}$ of all simulated timber boards the characteristic value of the tensile strength $f_{\mathrm{t}, \mathrm{k}}$ was calculated. Furthermore, the mean value $f_{\mathrm{t} \text {,mean }}$ and the COV are estimated assuming a Lognormal distribution; the results are summarised in Table 4. The estimated tensile strength of the simulated timber boards and the fitted Lognormal distribution are illustrated in Fig. 7 (left).

\subsubsection{Tensile stiffness}

The tensile stiffness $E_{\mathrm{t}, \text { mean }}$ of the timber boards is calculated with the tensile stiffness of the single timber board sections, in accordance with Hook's law for serial springs. Based on the simulations, the expected value of $E_{\mathrm{t}, \text { mean }}$ and the $\mathrm{COV}$ are estimated, assuming a Lognormal distribution (Table 4).

Table 4 Compilation of the simulated material properties [MPa] (compared with the required/recommended values given in literature)

\begin{tabular}{llllll}
\hline & \multicolumn{2}{l}{ Strength grade L25 } & & \multicolumn{2}{l}{ Strength grade L40 } \\
\cline { 5 - 6 } & Simulation & Literature & & Simulation & Literature \\
\hline$f_{\mathrm{t}}$ & 14.8 & $14.5^{\mathrm{a}}$ & & 27.2 & $26.0^{\mathrm{a}}$ \\
$f_{\mathrm{t}, \mathrm{k}}$ & 26.7 & - & & 44.5 & - \\
$f_{\mathrm{t}, \text { mean }}$ & 0.33 & $0.30^{\mathrm{b}}$ & & 0.28 & $0.30^{\mathrm{b}}$ \\
$\operatorname{COV}\left(f_{\mathrm{t}}\right)$ & & & & & \\
$E_{\mathrm{t}}$ & $10^{\prime} 400$ & $11^{\prime} 000^{\mathrm{a}}$ & & $14^{\prime} 800$ & $14^{\prime} 000^{\mathrm{a}}$ \\
$E_{\mathrm{t}, \text { mean }}$ & 0.15 & $0.13^{\mathrm{b}}$ & & 0.14 & $0.13^{\mathrm{b}}$ \\
$\operatorname{COV}\left(E_{\mathrm{t}}\right)$ & 0.15 & & & \\
$f_{\mathrm{t}, \mathrm{j}}$ & & $19.5^{\mathrm{c}}$ & & 30.6 & $31.0^{\mathrm{c}}$ \\
$f_{\mathrm{t}, \mathrm{j}, \mathrm{k}}$ & 21.2 & - & 43.5 & - \\
$f_{\mathrm{t}, \mathrm{j}, \text { mean }}$ & 30.1 & - & 0.20 & - \\
$\operatorname{COV}\left(f_{\mathrm{t}, \mathrm{j}}\right)$ & 0.20 & - & &
\end{tabular}

a According to EN 14081-4 (2009)

b According to JCSS (2006)

c According to EN 1194 (1999): $f_{\mathrm{t}, \mathrm{j}, \mathrm{k}} \geq 5+f_{\mathrm{t}, \mathrm{k}}$ 

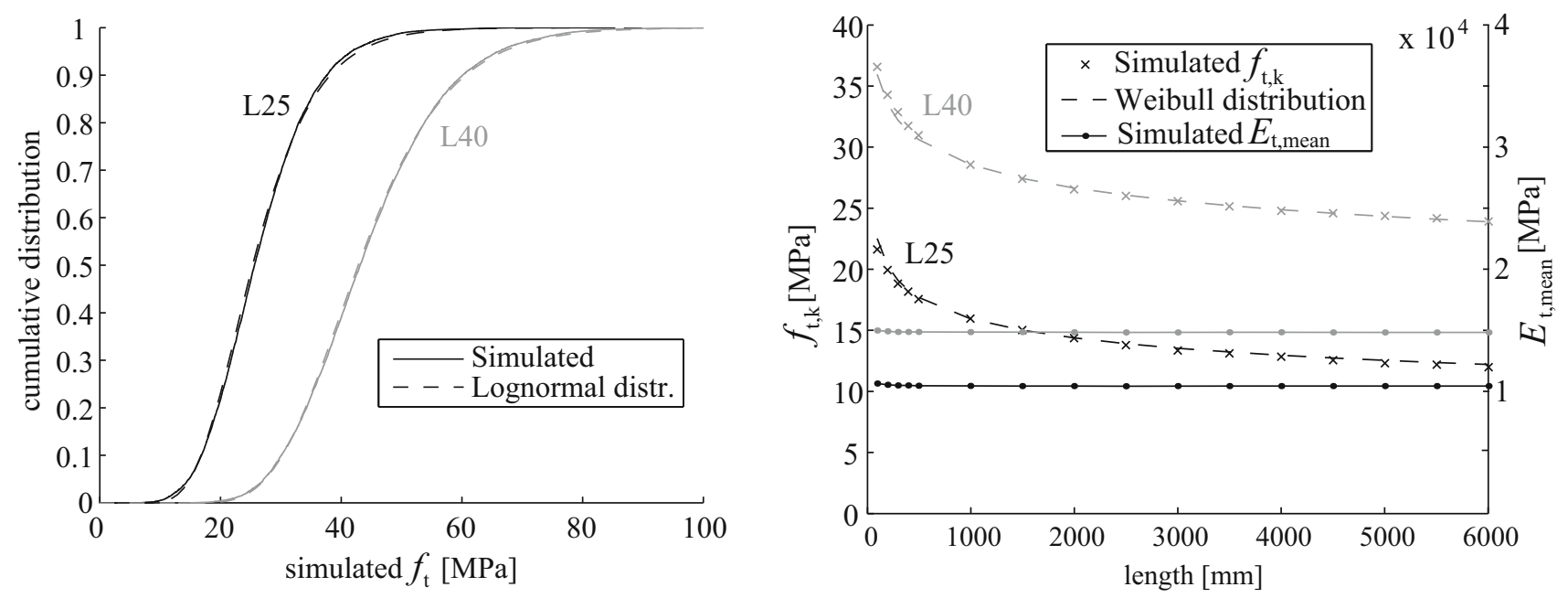

Fig. 7 (left) Cumulative distribution function of the predicted tensile strength $f_{\mathrm{t}}$, (right) length effect

\subsubsection{Length effect}

A further application of the model is the investigation of the length effect. Timber boards having different lengths are simulated. From the simulated timber boards the tensile strength and stiffness properties $\left(f_{\mathrm{t}}\right.$ and $\left.E_{\mathrm{t}}\right)$ are estimated and the corresponding characteristic values $\left(f_{\mathrm{t}, \mathrm{k}}\right.$ and $\left.E_{\mathrm{t}, \text { mean }}\right)$ are calculated. The results are illustrated in Fig. 7 (right). It is obvious that the tensile strength decreases with increasing board length, whereas no influence on the mean tensile stiffness can be detected.

The strength of a structural component that shows brittle failures can be explained by the weakest link theory (Weibull theory, according to Weibull 1939), which states that the load-bearing capacity of a structural component corresponds to load-bearing capacity of its weakest link. Keeping the probability of failure constant for two different lengths $l$ and $l_{\text {ref }}$, a relation between the load-bearing capacities can be calculated; Eq. (13), (see e.g. Barrett et al. 1995; Madsen and Buchanan 1986) Here, $l$ denotes the length of the specimen and $l_{\text {ref }}$ denotes the reference length.

$\frac{f_{\mathrm{t}}}{f_{\mathrm{t}, \mathrm{ref}}}=\left(\frac{l_{\mathrm{ref}}}{l}\right)^{-\eta}$

In Fig. 7 (right) the length effect is illustrated-reference length $l_{\text {ref }}=1620 \mathrm{~mm}$. With a chosen parameter $\eta=$ -0.15 for strength grade L25, and $\eta=-0.10$ for strength grade L40 good accuracy to the simulated data is identified. The identified parameters correspond to those found in the literature (see e.g. the literature compilation in Isaksson 1999). It seems that the influence of the length effect decreases with increasing quality of the timber boards. This can be explained by the lower variability of the material properties of higher strength grades.

\subsection{4 $\mathrm{tKAR}_{\text {limit }}$}

To model the tKAR-value of WS it is assumed that the grading process is not perfect, thus $\mathrm{tKAR}_{\text {limit }}=1$. However, to simulate a perfect grading process, any tKAR $\mathrm{Rimit}_{\text {lit }}$ can be considered in the presented approach. The strength grade L25 [EN 14081-4 (2009)] is comparable to the strength grade C24 [EN $338(2010)]: f_{\mathrm{t}, \mathrm{k}}=14.5 \mathrm{MPa}$ and $f_{\mathrm{t}, \mathrm{k}}=14.0 \mathrm{MPa}$, respectively. According to EN 1912 (2012) the strength grade $\mathrm{C} 24$ corresponds to visually graded timber S10. For $\mathrm{S} 10$ a knot cluster tKAR $\leq 0.50$ is acceptable, according to DIN 4074-1 (2008). Thus, $\mathrm{tKAR}_{\text {limit }}=0.50$ seems to be an accurate grading criterion for strength grade L25. Using $\mathrm{tKAR}_{\text {limit }}=0.50$, the tensile strength would slightly increase; e.g. $f_{\mathrm{t}, \mathrm{k}}$ increases $\approx 8 \%$. However, it has to be mentioned that for timber graded with GoldenEye-706 grading device no upper limit for knots was defined.

For the upper strength grade L40 a direct comparison to a visual grading criterion is not possible, as visual grading of Norway spruce is only allowed up to strength grade C30 [see EN 1912 (2012) and DIN 4074-1 (2008)]. However, a limitation $\mathrm{tKAR}_{\text {limit }}=0.40$ might be accurate. In that case $f_{\mathrm{t}, \mathrm{k}}$ increases $\approx 3 \%$.

\subsubsection{Model uncertainties-material model}

The material model (strength and stiffness model) is subjected to model uncertainties. They are expressed through the error term $\varepsilon \sim N\left(0, \sigma_{\varepsilon}\right)-$ Eq. (10). The sensibility of the error term $\varepsilon$ on the characteristic value of the tensile strength $f_{\mathrm{t}, \mathrm{k}}$, is investigated. It is obvious that with an increase of $\sigma_{\varepsilon}$ the estimation of $f_{\mathrm{t}, \mathrm{k}}$ will decrease; Fig. 8 . The illustration indicates that the model is sensitive to the chosen $\sigma_{\varepsilon}$, in particular for higher strength grades. 


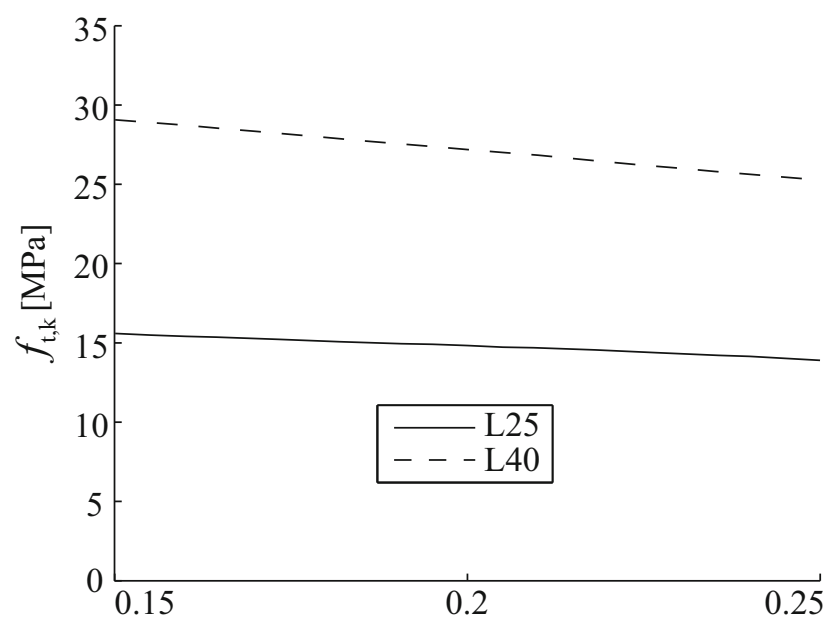

Fig. 8 Influence of $\sigma_{\varepsilon}$ on the characteristic value of the tensile capacity of timber boards

To consider the within-member correlation $\varepsilon$ is separated into two parts: $\varepsilon_{1}$ for the uncertainty of the mean material properties (constant within one timber board), and $\varepsilon_{2}$ for the uncertainty of the strength/stiffness reduction of each particular WS. A ratio between these two parts of $\varepsilon_{1}: \varepsilon_{2}=2: 1$ is chosen in accordance with the investigations of Colling (1990). However, for the presented material model this assumption was investigated. The influence of $\varepsilon_{2}$ is larger, because on average more than one WS occurs within one timber board: $f_{\mathrm{t}, \mathrm{k}}\left(\varepsilon_{1}, \varepsilon_{2} \mid \varepsilon_{1}<\varepsilon_{2}\right)$ $<f_{\mathrm{t}, \mathrm{k}}\left(\varepsilon_{1}, \varepsilon_{2} \mid \varepsilon_{1}>\varepsilon_{2}\right)$. However, the influence is rather small; e.g. $\leq \pm 2 \%$ for the characteristic value of the tensile strength.

\subsubsection{Statistical uncertainties}

To predict the characteristic value of the tensile strength $f_{\mathrm{t}, \mathrm{k}}$ of timber boards, four models $\left(d, \mathrm{tKAR}, E_{\mathrm{dyn}, \mathrm{F}}\right.$, and $\left.f_{\mathrm{t}, \mathrm{wS}}\right)$ with altogether 11 parameters have to be taken into account. The parameters of the four models are not or only marginally correlated, thus their correlation is not considered. However, for all parameters the expected values and their statistical uncertainties, as well as their correlations (correlations between parameters of the same model) were identified. Assuming that the statistical uncertainties of the parameters are Normal distributed the statistical uncertainties of $f_{\mathrm{t}, \mathrm{k}}$ are calculated.

For this purpose, the characteristic value of the tensile strength $f_{\mathrm{t}, \mathrm{k}}$ is calculated 100 times, each time based on $10^{4}$ simulated timber boards. The variability of $f_{\mathrm{t}, \mathrm{k}}$ is $\operatorname{COV}\left(f_{\mathrm{t}, \mathrm{k}}\right)=0.019$. Thus, it seems that the influence of the statistical uncertainties is rather small.

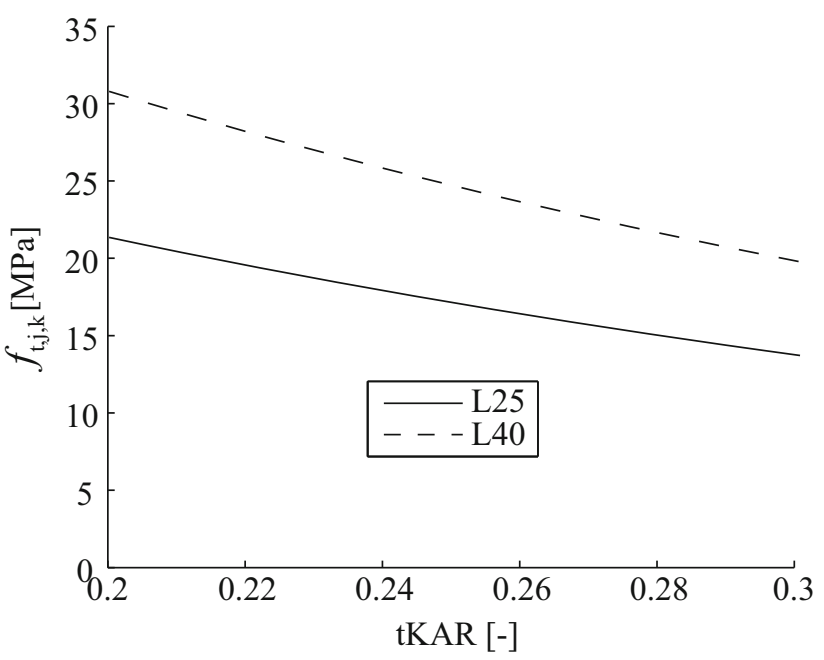

Fig. 9 Influence of tKAR on the characteristic value of the tensile capacity of finger joint connections

\subsection{Finger joint connections}

The introduced approach can also be used to model the tensile strength of FJ $\left(f_{\mathrm{t}, \mathrm{j}}\right)$. Therefore, two independent timber boards (clear wood) are simulated. $f_{\mathrm{t}, \mathrm{j}}$ is calculated just as a WS, within the weaker timber board, having a specific tKAR-value; here tKAR $=0.2$. Based on a sufficient amount of simulated FJ, the mean value and the characteristic value of the tensile strength $\left(f_{\mathrm{t}, \mathrm{j}, \text { mean }}\right.$ and $\left.f_{\mathrm{t}, \mathrm{j}, \mathrm{k}}\right)$ are calculated. The results are summarised in Table 4.

In the present model it is assumed that the tensile strength of a FJ corresponds to the tensile strength of a WS having specific tKAR-value. It is obvious that a larger tKAR-value leads to a decrease of $f_{\mathrm{t}, \mathrm{j}}$. This influence is illustrated in Fig. 9. Considering that the required values are 19.5 and $31.0 \mathrm{MPa}$, respectively, it seems that the chosen value $\mathrm{tKAR}=0.2$ is quite realistic. Using a higher tKAR-value, the required values of the characteristic tensile strength are significantly underestimated; e.g. tKAR $=$ 0.25 led to $f_{\mathrm{t}, \mathrm{j}, \mathrm{k}}=17.0 \mathrm{MPa}$ and $f_{\mathrm{t}, \mathrm{j}, \mathrm{k}}=24.5 \mathrm{MPa}$, respectively.

\section{Conclusion}

In this paper, a probabilistic model for the presentation of strength and stiffness related indicators of two strength grades (L25 and L40) is developed. The specific characteristic of this model was that the natural growth characteristic of timber is considered; i.e. the position and the characteristics of knot clusters can be simulated. 
The geometrical setup of the timber boards is simulated by the distance between knot clusters. The characteristics of knot clusters is modelled with a knot parameter, and the dynamic modulus of elasticity is used to simulate the mean material properties of the timber boards. For all three parameters the most suitable distribution functions were selected in a way that the basic population of each indicator is best represented. Based on the knot parameter and the dynamic modulus of elasticity the tensile strength and the tensile stiffness of timber board sections and finger joint connections are estimated using material models.

The application of the approach is illustrated. For this purpose, timber boards and finger joint connections were simulated and their tensile related material properties were estimated. Both, the tensile strength and the tensile stiffness of the simulated timber boards and the simulated finger joint connections show a wide agreement with required/recommended values given in literature; i.e. the characteristic values, mean values and variability of the material properties are reasonable. As a result of the wide agreement it seems to be reasonable to apply the presented approach to simulate the setup of solid timber and engineered wood products (e.g. glued laminated timber and cross laminated timber).

The presented approach can also be used to investigate the influence of the length effect of timber boards or the grading process. In this paper two examples are investigated: (a) the influence of the timber board length on the tensile capacity and (b) the influence of a perfect grading process, where every timber board with a knot cluster above a specific tKAR-value is sorted out.

\section{References}

Barrett J, Lam F, Lau W (1995) Size effects in visually graded softwood structural lumber. J Material Civil Eng 7(1):19-30

Benjamin JR, Cornell CA (1970) Probability, statistics, and desision for civil engineers. MCGraw-Hill Book Company

Blaß H, Frese M, Glos P, Denzler J, Linenmann P, Ranta-Maunus A (2008) Reliability of spruce-glulam with modified set-up (in German), vol 11. KIT Scientific Publishing

Colling F (1990) Bending strength of glulam beams depending on strength related parameters (thesis, in German). Versuchsanst. für Stahl, Holz und Steine

Colling F, Dinort R (1987) The knot frequency of conifer timber used in glulam factories (in German). Holz Roh- Werkst 45(1):23-26

Czmoch I, Thelandersson S, Larsen H (1991) Effect of within member variability on bending strength of structural timber. In: Proceedings of the 24th Meeting, International Council for Research and Innovation in Building and Construction, Working Commission W18 - Timber Structures, Oxford, United Kingdom, CIB-W18, Paper No. 24-6-3

DIN 4074-1 (2008) Strength grading of wood-Part 1: Coniferous sawn timber; German version
Ehlbeck J, Colling F, Görlacher R (1985) Influence of fingerjointed lamellae on the bending strength of glulam beams (in German). Holz Roh- Werkst 43(8):369-373

EN 1194 (1999) Timber structures-glued laminated timberstrength classes and determination of characteristic values; German version

EN 14081-4 (2009) Timber structures-strength graded structural timber with rectangular crosssection-Part 4. In: Machine grading-grading machine settings for machine controlled systems; German version

EN 1912 (2012) Structural timber-strength classes-assignment of visual grades and species; German version

EN 338 (2010) Structural timber-strength classes; german version

EN 384 (2004) Determination of characteristic values of mechanical properties and density; german version

EN 408 (2003) Timber structures-structural timber and glued laminated timber - Determination of some physical and mechanical properties; German version

Faber M (2012) Statistics and Probability Theory. In Pursuit of Engineering Decision Support, vol 18. Springer

Fink G (2014) Influence of varying material properties on the loadbearing capacity of glued laminated timber-Diss. ETH NO. 21746. PhD thesis, ETH Zurich, Zurich, Switzerland

Fink G, Kohler J (2011) Multiscale Variability of Stiffness Properties of Timber Boards. In: ICASP Applications of Statistics and Probability in Civil Engineering. Zurich, Switzerland

Fink G, Kohler J (2012) Non-destructive test to determine the modulus of elasticity of timber boards (in German). IBK Report No. 339, ETH Zurich, Zurich

Fink G, Kohler J (2014) Model for the prediction of the tensile strength and tensile stiffness of knot clusters within structural timber. Eur J Wood Prod 72(3):331-341

Giudiceandrea F (2005) Stress grading lumber by a combination of vibration stress waves and $\mathrm{x}$-ray scanning. In: Proceedings of the 11th International Conference on Scanning Technology and Process optimization in the wood Industry (ScanTech 2005), Las Vegas

Görlacher R (1984) A new method for determining the modulus of elasticity of timber (in German. Holz Roh- Werkst 42:219-222

Görlacher R (1990) Stress grading of laminates according to DIN 4074 by measuring longitudinal vibrations (in German). Bauingenieur 65:517-522

Heimeshoff B, Glos P (1980) Tensile Strength and MOE in Bending of Spruce Laminates (in German). Holz Roh- Werkst 38(2):51-59

Isaksson T (1999) Modelling the variability of bending strength in structural timber. PhD thesis, Lund Institute of Technology

JCSS (2006) Probabilistic Model Code Part III - Resistance Models (3.05 Timber). http://www.jcss.byg.dtu.dk/Publications/ Probabilistic_Model_Code

Kersken-Bradley M, Rackwitz R (1991) Stochastic modeling of material properties and quality control. In: JCSS Working Document, IABSE-publication

Kline D, Woeste F, Bendtsen B (1986) Stochastic model for modulus of elasticity of lumber. Wood and Fiber Science 18:228-238

Köhler J, Faber MH (2004) Proposal for a probabilistic model code for design of timber structures. In: Proceedings of the 37th Meeting, International Council for Research and Innovation in Building and Construction, Working Commission W18 - Timber Structures, Edinburgh, UK, CIB-W18, Paper No. 37-104-1

Köhler J, Sørensen JD, Faber MH (2007) Probabilistic modeling of timber structures. Structural safety 29(4):255-267

Kohler J, Brandner R, Thiel A, Schickhofer G (2013) Probabilistic characterisation of the length effect for parallel to the grain tensile strength of central european spruce. Engineering Structures 56:691-697 
Lam F, Varoglu E (1991a) Variation of tensile strength along the length of lumber. Wood Sci Technol 25(5):351-359

Lam F, Varoglu E (1991b) Variation of tensile strength along the length of lumber. Wood Sci Technol 25(6):449-458

Madsen B, Buchanan AH (1986) Size effects in timber explained by a modified weakest link theory. Canadian Journal of Civil Engineering 13(2):218-232

Pellicane P, Stanfill-McMillan K, Tichy R (1987) Effects of knots near the fingers of finger-jointed dimension lumber. Forest products journal 37(5):13-16

Samson M (1985) Potential of finger-jointed lumber for machine stress-rated lumber grades. Forest Products Journal 35(7/ 8):20-24
SIA 265-1,(2009) Timber Structures - Supplementary Specifications. German version, Schweizer Ingenieur- und Architektenverein, Zurich, Switzerland

Taylor SE, Bender DA (1991) Stochastic model for localized tensile strength and modulus of elasticity in lumber. Wood and Fiber Science 23(4):501-519

Weibull W (1939) A statistical theory of strength of materials. Nr. 151, Royal Swedish Institute for Engineering Research 